\title{
Purple Grape Juice Improves Performance of Recreational Runners, But the Effect is Genotype Dependent: A Double Blind, Randomized, Controlled Trial
}

\author{
Bruno Rafael Virginio Sousa \\ Universidade Federal da Paraíba (UFPB) \\ Lydiane de Lima Tavares Toscano \\ Universidade Federal da Paraíba (UFPB) \\ Eder Jackson Bezerra Almeida Filho \\ Universidade Federal da Paraíba (UFPB) \\ Klécia Farias Sena \\ Universidade Federal da Paraíba (UFPB) \\ Matheus Silveira Costa \\ Universidade Federal da Paraíba (UFPB) \\ Rebeka Correia de Souza Cunha \\ Universidade Federal da Paraíba (UFPB) \\ Jullyana de Souza Siqueira Quintans \\ Universidade Federal de Sergipe (UFS) \\ Luana Heimfarth \\ Universidade Federal de Sergipe (UFS)
}

Aline Telles Biasoto Marques

Empresa Brasileira de Pesquisa Agropecuária

Darcilene Fiuza Silva

Universidade Federal da Bahia

Luis Felipe Castelli Correia Campos

Universidade de Bío-Bío

Darlene Camati Persuhn

Universidade Federal da Paraíba (UFPB)

Alexandre Sérgio Silva ( $\sim$ alexandresergiosilva@yahoo.com.br)

Universidade Federal da Paraíba (UFPB)

\section{Research Article}

Keywords: Antioxidant, ergogenic food, polymorphisms, nutrigenetic

Posted Date: February 7th, 2022 
DOI: https://doi.org/10.21203/rs.3.rs-1323973/v1

License: (c) (1) This work is licensed under a Creative Commons Attribution 4.0 International License. Read Full License 


\section{Abstract}

\section{Background:}

We examined the influence of superoxide dismutase 3 (SOD3) Arg213Gly and Peroxisome Proliferator-Activated a-Receptor (PPARa) 7G/C polymorphisms to a single dose of purple grape juice supplementation on time-toexhaustion running test, redox balance and muscle damage in recreational runners.

\section{Methods:}

Forty-seven male recreational runners performed a running test until exhaustion after supplementation with grape juice or a control drink. Serum total antioxidant capacity (TAC), malondialdehyde (MDA), plasma nitrite (NO), creatine kinase (CK) and lactate dehydrogenase (LDH) were measured pre and post exercise. Also, polymorphisms were analyzed in DNA extracted from the oral mucosa.

\section{Results:}

Grape juice improved the time-to-exhaustion. When analyzed by genotype, the recreational runners with GG+CG genotypes of the SOD3 gene had greater time-to-exhaustion than the CC genotype, but was no different for the PAPRa gene. A slight difference was noted in TAC, since the CC genotype of the SOD3 gene showed higher TAC values in the post-exercise compared to the baseline and with pre-exercise, but these values did not increase compared to the CG+GG group, respectively. The SOD3 and PPARa genes were similar at all times for the other biochemical variables.

\section{Conclusion:}

The ergogenic effect of grape juice was genotype-dependent for SOD3 Arg213Gly. However, biochemical redox balance markers did not explain this difference.

\section{Background}

Purple grapes and derivatives present high antioxidant and anti-inflammatory properties [1,2]. These characteristics are attributed to their rich composition in flavonoids. These include flavanols, flavonols and anthocyanidins [3], as well as non-flavonoid compounds, such as phenolic acid and resveratrol [4]. This antioxidant action was previously demonstrated in studies in the field of exercise training in which purple grape seed extract [5] and purple grape bagasse extract [6,7] reduced oxidative stress markers in an animal model.

In humans, recreational runners supplemented with purple grape juice $(10 \mathrm{~mL} / \mathrm{kg} /$ day for 28 days $)$ increased their time-to-exhaustion running test time by $15 \%$, accompanied by an increase in total antioxidant capacity and reduction in inflammatory activity, even without any protection against muscle damage induced by the exercise session [8]. This ergogenic effect of the purple grape was recently confirmed in another study that employed a single dose $(10 \mathrm{~mL} / \mathrm{kg})$. It increased the time-to-exhaustion in runners $(18.7 \%)$ to an even greater extent, accompanied by increased total antioxidant capacity [9].

Although promising, these outcomes displayed high variability in response to supplementation, in which over 28 days [8] $67 \%$ were responsive to grape juice improved performance within a range of $3 \%$ to $73 \%$, while $33 \%$ were 
not responsive to grape juice. In the study in which a single dose was administered [9], improvement among 70\% who showed responsiveness to juice and improved performance was between $1 \%$ and $74 \%$, and $30 \%$ were not responsive to grape juice.

In an attempt to explain this variability found in response to purple grape juice supplementation, genetic polymorphisms emerge as a potential influencing factor [10]. The genetic influence was observed with caffeine supplementation in which cyclists with GG genotype for CYP1A2 (C/A) polymorphism in cytochrome P450 displayed a greater ergogenic effect compared to the $C$ allele [11]. When pequi oil was given to runners, TG genotyped athletes showed an aerobic advantage compared to GG genotyped athletes [12]. In addition, soccer players with CC genotype for the C34T polymorphism of the AMPD1 gene had a better response to creatine supplementation [13].

Since previous studies show that the increase in physical performance provided by grape juice was accompanied by antioxidant activity, we can assume that one of the genes that controls antioxidant activity, superoxide dismutase 3 (SOD3), can modulate the response of this enzyme and explain the better performance promoted by grape juice. In fact, the SOD3 enzyme is the main plasma SOD and is released by the interstitial space which participates in the elimination of superoxide (02-) [14]. Interestingly, a naturally occurring Arg213Gly polymorphism in this binding region [15) increases the extracellular SOD concentration in the plasma of homozygous individuals 10- to 30-fold [16]. Furthermore, the Peroxisome Proliferator-Activated a-Receptor (PPARa) regulates both systemic redox activity [17] and the oxidative capacity of skeletal muscles [18, 19]. In addition, it is involved in mitochondrial activity, which directly influences endurance exercises [20].

Based on this evidence, we tested the hypothesis that the SOD3 Arg213Gly and PPARa 7G/C polymorphisms influence the redox balance and physical performance resulting from the supplementation with a single dose of grape juice. The goal of this study was to investigate the effect of a single dose of grape juice on performance in a time-to-exhaustion test in runners and verify the influence of SOD3 Arg213Gly and PPARa 7G/C polymorphisms on the time-to-exhaustion and redox balance in recreational runners.

\section{Materials And Methods}

\subsection{Study type and characterization of subjects}

This is a randomized, double-blind, cross-over, controlled clinical trial with number RBR-4d9dmqz in the Brazilian Clinical Trials Registry (ReBEC). The sample size was established a priori, according to an increase in time-toexhaustion from $59.2 \pm 27.8$ minutes to $68.4 \pm 29.2$ minutes in response to purple grape juice by Toscano et al. [9]. This increase represented an effect size of $d=0.92$, so that a minimum of 13 subjects were assigned considering an a error of 0.05 and a $\beta$ error of 0.80 using GPower 3.1 software program (Franz Faul, Universitat Kiel, Germany). However, as the subjects in this study were categorized by genotype, a higher number of participants was needed. Therefore, the study was conducted with 47 male recreational runners. After genotyping, the group with the smallest sample size (CC of the SOD3 gene) was left with 12 subjects.

Inclusion criteria were defined as recreational runners should have been training for at least one year with a frequency of at least four weekly sessions and for at least two months without interruption and taking part in competitions from 5 kilometers to 21 kilometers or marathon regularly. They also should not have any chronic condition or degenerative diseases, did not smoke, and were not using any long-term medication. Furthermore, 
subjects should not consume purple grapes or their derivatives often; and/or dietary supplements, vitamins or bioactive substances present in the grape (polyphenols). Athletes who suffered from skeletal muscle injuries, altered dietary habits or had inconsistent training patterns, started using medication or did not perform some of the study experimental procedures were also excluded. Figure 1 shows the randomization, allocation and followup of subjects, according to the inclusion criteria.

\section{> INSERT FIGURE 1 《<}

\subsection{Study design}

Figure 2 shows the experimental design of the study. First, the athletes performed the maximum aerobic capacity test. The next 2 weeks they participated in the experimental procedures by performing the test run to exhaustion, drinking grape juice or control drink prior to the test. The order of these procedures was determined randomly (in blocks) by a researcher who did not participate in the other experimental protocols using www.randomizer.org. Subjects (athletes) and the researcher, who gave the test to exhaustion, were blinded as to the supplementation tested. Heart rate and perception of effort were recorded every 10 minutes throughout the test. Blood samples were taken before supplementation (grape juice or control drink), immediately before the running test until exhaustion (two hours after supplementation) and immediately at the end of the test to measure the redox balance, muscle damage and plasmatic nitrite. Furthermore, quality of sleep, social stress and self-referred recovery were evaluated before each test. An oral mucosa sample was collected at the end of the experiment for DNA genotyping.

\section{$\gg$ INSERT FIGURE $2 \ll$}

\subsection{Aerobic capacity test}

Volunteers performed a 3200-m running test in the week before implementing the experimental protocol in order to characterize their aerobic capacity according to the protocols proposed by Weltman et al. [21]. Running tests to estimate maximum aerobic capacity were carried out with each athlete individually. The adopted 3200-m test protocol was performed on a 400-m lane of an official athletic track certified for international competitions. The athletes performed a 5-minute warm-up on the treadmill with spontaneous speed. They were instructed to start the test and complete the proposed distance in the shortest time possible. V02max was estimated using the following equation: V02max $(\mathrm{ml} . \mathrm{kg}-1 . \mathrm{min}-1)=118.4-4.774 \times(\mathrm{T})$, where $\mathrm{T}$ is the time in minutes and decimal fraction.

\subsection{Preexperimental procedures}

The athletes did not exercise for 48 hours and remained 10 hours overnight fasting prior to testing and were instructed to not consume grapes or derivatives, nor eat any foods rich in antioxidants. Moreover, they did not consume caffeine or alcoholic drinks in the 24 hours prior to the test sessions.

The volunteers arrived at the laboratory at 6:30 am to start the tests on the two days of experimental protocols. First, they were acclimatized in an air-conditioned room at 22 and $25^{\circ} \mathrm{C}, \mathrm{RH} 65 \%$ and sat at rest for 10 minutes before starting the experimental protocol.

\subsection{Body composition and nutritional assessment}


The athletes were characterized for body composition by measuring height with a portable stadiometer (Sanny, Standard, São Paulo, Brazil), and then body composition was assessed using Bioimpedance (InBody 570 Biospace ${ }^{\circledR}$, San Francisco, California, USA), with multifrequency analysis on an eight-point tetrapolar electrode system. They were also instructed not to use caffeinated or alcoholic beverages during the previous 24 hours and not to drink water on the morning of the evaluation.

Food intake was evaluated using a 24-hour food record [22] employed twice before the time-to-exhaustion tests. This was done to characterize food consumption in the 24 hours prior to the experimental tests (Avanutri®, Rio de Janeiro, Brazil).

\subsection{Characterization of grape juice and supplementation protocol}

The experimental beverage employed in this study was purple grape juice from Cooperativa Vinícola Garibaldi (Garibaldi, Serra Gaúcha, Brazil) produced from grapes of the Isabel, Bordeaux and Concord (V. labrusca) varieties. According to the manufacturer, the juice was characterized as being a natural, whole (100\% grape juice) and non-alcoholic drink with no added sugar, water, flavorings or preservatives. Furthermore, $200 \mathrm{~mL}$ of the grape juice contains $130 \mathrm{kcal}$ and $32 \mathrm{~g}$ of carbohydrates and does not contain a significant amount of protein, total fat, saturated fat, trans fat, dietary fiber or sodium.

The antioxidant composition was determined by free radical scavenging activities using DPPH (2,2 diphenyl-1picrylhydrazyl) according to Brand-Williams, Cuvelier and Berset [23], and ABTS (2,2'-azinobis-3ethylbenzthiazoline- 6 sulfonic acid) $[24,25]$. The total phenolic content was determined according to the methodology described by Folin-Ciocateau [26]. The quantification of specific classes of polyphenols was performed in the present study, in which the quantification of the phenolic compounds was performed by highperformance liquid chromatography (HPLC) using a Waters 2695 Alliance system (Milford, MA, USA) equipped with a diode array detector (DAD) and fluorescence detector (FLD) according to a method validated by EMBRAPA. The control drink was (maltodextrin) artificial grape flavor, which presented the same amount of carbohydrates, calories and volume [8], but without polyphenols.

The athletes had a standardized breakfast which consisted of a sandwich ( $50 \mathrm{~g}$ of whole meal bread $+34 \mathrm{~g}$ of processed white light cheese $=152 \mathrm{kcal} ; 21.8 \mathrm{~g}$ of carbohydrates; $7.4 \mathrm{~g}$ of proteins; $3.6 \mathrm{~g}$ of fat; $4.0 \mathrm{~g}$ and purple grape juice or control drink, according to previous randomization. They received $10 \mathrm{~mL} / \mathrm{kg} /$ day [9] of supplementation of grape juice or control drink two hours before the running test to exhaustion, so that they could reach greater bioavailability of the polyphenolic compounds present in the drink [27]. Volunteers and researchers involved in the experimental procedures were blinded to supplementation. The beverages also had similar color and flavor.

\subsection{Subjective stress, sleep and recovery/rest}

To characterize the physiological conditions in the two pre-experimental test moments, the Profile of Mood States questionnaire (POMS) [27] was given to each athlete to examine the psychometric state of Total Humoral Disturbance (THD). In addition, the Stress and Recovery Questionnaire for athletes (RESTQ-Sport) [29] was used to evaluate the state of stress and recovery from everyday situations that are potentially stressful and restful. The EPWORTH-Brazilian Sleepiness Scale (ESS-BR) [30] was employed to assess the occurrence of daytime sleepiness. 


\subsection{Run to exhaustion test}

The athletes performed a free warm-up of between 5 and 7 minutes before starting the test. Next, they performed the running test to exhaustion on a treadmill ergometer (Moviment, São Paulo, Brazil), with the speed set at $80 \%$ of V02max [31, 32], converting this value to belt speed according to a previous study [33]. Heart Rate (Polar FT1, Kempele, Finland) and the Borg Rating of Perceived Exertion Scale [34] was monitored every 10 minutes during the test. The test was interrupted when the athlete demonstrated inability to keep up with the treadmill speed and through verbal confirmation between 19 and 20 on the effort scale. The total running time was recorded at the end of the test. The electronic panel of the treadmill was covered so that athletes could not see the race data, especially the time elapsed in order to ensure methodological rigor. The test was performed under controlled temperature and relative humidity $(\mathrm{RH})\left(22\right.$ and $\left.25^{\circ} \mathrm{C}, \mathrm{RH} 65 \%\right)$ respectively, measured by a thermohygrometer (TFA HT-7429, São Paulo, Brazil).

\subsection{Genotyping}

Samples of the oral epithelial cells in the subjects were collected by mouth washing with sucrose, and then the DNA was extracted. The genotypes were determined using the RFLP technique (Restriction Fragment Length Polymorphism) in polymerase chain using specific primers. The sense primer (5'CGCCAGGCGCGGGAACACTCAG-3') and antisense primer (5'-GGCGGACTTGCACTCGCTCTCG-3') were used for the SOD3 Arg213Gly polymorphism. Amplification was performed according to a protocol described by Laddha [35]. The PCR product was digested using the restriction enzyme Mwol (New England 307 Biolabs, Ipswich, MA, USA) and taken to a dry incubation at $60^{\circ} \mathrm{C}$ for 3 hours.

The sense (5'-ACAATCACTCCTTAAATATGGTGG-3') and antisense primers ( $5^{\prime}$ AAGTAGGGACAGACAGGACCAGTA-3') were respectively used for the PPARa 7G/C polymorphism. Amplification occurred according to the method proposed by Pishva et al. [36]. The PCR product was digested using the Taqa I enzyme (New England 316 Biolabs, Ipswich, MA, USA) and taken to incubation at $65^{\circ} \mathrm{C}$ for 3 hours. Next, they were evaluated by electrophoresis on $15 \%$ polyacrylamide gel and staining with $0.5 \%$ silver nitrate.

\subsection{Redox balance, plasma nitrite and damage muscle}

The oxidative activity was evaluated by lipid peroxidation that could be quantified by the metabolic product of malondialdehyde (MDA) through a thiobarbituric acid reaction in plasma [37]. The antioxidant activity was determined through total antioxidant capacity (TAC). It was quantified in plasma via the free radical scavenging activity of 2,2-diphenyl-1-picrylhydrazyl [23]. Plasma nitrite concentrations were determined by the Griess reaction that quantifies the nitrite in the sample through the diazotization reaction, forming a pinkish chromophore [38]. Muscle damage was measured by Creatine kinase (CK) using the catalytic activity method. Lactate dehydrogenase $(\mathrm{LDH})$ concentrations were measured using the pyruvate-lactate method via specific commercial kits (Labtest, Minas Gerais, Brazil). The absorbances were obtained in Labmax 240 premium automatic analyzer (Labtest, Minas Gerais, Brazil) at a wavelength of $340 \mathrm{~nm}$.

\subsection{Statistical analysis}

Data were presented as mean \pm standard deviation (SD). Normality and homogeneity of data were assessed using the Shapiro-Wilk and Levene tests, respectively. Data that did not show a normal distribution were ranked 
according to Templeton [39] for normalization. Analyzes were performed by being subdivided according to the genotype considering the presence or absence of the allele with the polymorphism characteristic. Athletes were divided based on the presence of the G allele (GG+CG genotypes) or CC genotype for the SOD3 Ag213Gly polymorphism; while subjects were categorized according to the presence of the $\mathrm{C}$ allele (CC+GC genotypes) or GG genotype for the PPARa 7G/C polymorphism. An independent t-test was used in order to compare the results of pre-experimental conditions (nutritional intake, sleep, mood, general stress, physical recovery and plasma biomarkers) and differences between absolute deltas in time-to-exhaustion. The results for biomarker levels were analyzed using two-way ANOVA for multiple comparisons with Bonferroni's post-hoc test. The effect size was calculated using the Cohen's $d$ test for independent samples using the GPower Statistics 3.1 program and then classified according to Cook, Cook and Therrin [40] into small ( $d=0.00-0.40)$, medium $(d=0.50-0.70)$, large ( $d$ $=0.80-1.00)$ or very large $(d \geq 1.30)$ effect sizes. This provided information on the power of the practical application of the intervention. Moreover, an individual analysis (simple subject analysis) was performed on the exhaustion time variable to demonstrate the variability of the athletes' responses in running performance. Pvalues $<0.05$ were considered statistically significant. SPSS was used for data treatment (v. 23, IBM SPSS, Chicago, IL, USA).

\subsection{Ethical statement}

The study was conducted entirely in accordance with the Declaration of Helsinki. Its protocol was approved by the Research Ethics Committee of the Center for Health Sciences, Federal University of Paraiba (protocol no. 2.196.523). The subjects signed an informed consent form according to Resolution 466/12 of the National Health Council (Brazil), and informed consent was also obtained from all of the subjects before the inclusion in the study.

\section{Results}

\subsection{Characterization of experimental and control drink}

The grape juice had $13.0 \mu \mathrm{Mol}$ Trolox $/ \mathrm{mL}$ of DPPH, 9.5 ATT $\mu \mathrm{Mol}$ Trolox $/ \mathrm{mL}$ of ABTS and $3106.6 \mathrm{mg} / \mathrm{L}$ of total phenolics. The main polyphenols found in the experiments of the present study are shown in Table 1. No significant values of antioxidant compounds were found in the control drink (maltodextrin).

\section{$\gg$ INSERT TABLE 1 <}

\subsection{Characterization of participants}

Baseline characteristics of the general group and the experimental group categorized by genotypes are shown in Table 2. It was observed that the CC genotype was more frequent 35 (74.5\%) in the Arg213Gly polymorphism of the SOD3 gene, followed by the CG genotype $11(23.4 \%)$, while the GG genotype (characteristic of the polymorphism) was observed in only one athlete (2,0\%). The frequency found for the PPARa 7G/C polymorphism was $28(60.7 \%)$ for the GG genotype; 15 (32.2\%) for GC and 4 (7.1\%) for the CC genotype. Therefore, because there was almost an absence of GG genotype in SOD3 Arg213Gly, the group was categorized according to the presence of the allele in: (CG + GG or CC). Moreover, the categorization for PPARa 7G/C was according to the presence of the allele in: $(\mathrm{GC}+\mathrm{CC}$ or $\mathrm{GG})$. 
The runners had maximum oxygen consumption below elite runners [41], characterizing them as recreational athletes. They were young adults, with anthropometric characteristics of eutrophic and body fat characteristic for runners [42]. They had at least six and a half years of training in running and trained at least four times a week, with an average weekly distance of $40 \mathrm{~km}$. In addition to running training, they performed complementary physical activities, such as cycling, swimming, team sports, wrestling, weight training and pilates. The genotypic groups were similar in all of these characteristics, except athletes with CC genotype for the SOD3 gene who performed more weekly complementary activities $(p<0.04)$ and presented a higher body fat percentage $(p<$ 0.03).

\section{$\gg$ INSERT TABLE $2 \ll$}

Table 3 depicts that athletes in the grape juice and control drink procedures were similar at baseline conditions with the exception of plasma nitrite and CK. These were higher in the control procedure $(p<0.03$ and $p<0.04$, respectively). The redox balance, nitrite and muscle damage biomarkers were similar for different genotypes. The intake of macronutrients and micronutrients was similar in the experimental and control procedures. When subdivided by genotype, carbohydrate intake was higher in the group with GG+CG genotype for the SOD3 gene than in the group presenting the CC genotype $(p<0.00)$. There was a difference in zinc intake for the PPARa, which was higher in athletes with GG genotype $(p<0.00)$.

Physiological self-reported conditions prior to each test (sleep, mood, general stress and physical recovery) were similarly comparable when contrasting both procedures. When subdivided by genotypes, sleep quality (hours) was superior in the CC genotype $(p<0.01)$ versus the $G G+C G$ genotype for the SOD3 gene. Sleep quality (sleepiness) was superior in the CC+GC genotype ( $<$ 0.02) versus $G G$ genotype for the PPARa gene. The mood state component was shown to be higher in the group with GG+CG genotype $(p<0.00)$ in comparison to the CC genotype. The results were similar between each genotype for the other variables.

\section{$\gg$ INSERT TABLE $3<<$}

\subsection{Physical Performance}

The athletes showed significantly higher performance after supplementation with the grape juice compared to the control drink (57.2 \pm 17.6 versus $54.0 \pm 18.9$ minutes, $p<0.02 ; d=0.17$, representing an improvement of $10.1 \%$ ( $0.8 \mathrm{~km}$ of distance). The analysis of a single subject for physical performance in the running test for each athlete showed that 31 (65.9\%) of the 47 runners evaluated were responsive to grape juice supplementation and presented better physical performance, while 16 (34.1\%) were not responsive.

The data categorized according to the genotypic groups are presented in Figure 3 (panel A). Athletes with GG+CG genotypes showed greater time-to-exhaustion for the SOD3 gene than the CC genotype (58.4 \pm 18.7 vs $53.8 \pm$ $14.2 ; 3.4 \pm 9.7$ minutes more). This outcome was accompanied by an effect size of $d=0.70$. Regarding the PPARa gene, time-to-exhaustion was similar between athletes with CC+GC genotypes ( $n=24)$ and the GG genotype $(n=23)$.

The individual analysis of the athlete's performance test is displayed in Figure 3, panels B and C for the SOD3 gene and panel D and E for the PPARa gene. For the SOD3 gene, it was verified that 10 (83.3\%) out of 13 runners with $\mathrm{GG}+\mathrm{CG}$ genotypes were responsive to grape juice supplementation and improved their time-to-exhaustion, 
while $3(16.7 \%)$ were not responsive. However, only $21(60 \%)$ of the athletes with CC genotype were responsive to grape juice and presented superior time-to-exhaustion, and 14 (40\%) were not responsive, maintaining or worsening their time-to-exhaustion. For the PPARa gene, 16 (66.6\%) athletes with the $\mathrm{C}$ allele were responsive to grape juice and increased their time-to-exhaustion, and 7 (33.4\%) were not responsive. Finally, for athletes with $\mathrm{G}$ allele, 15 (65.2\%) were responsive to grape juice and increased their running performance, while $8(34.8 \%)$ were not responsive.

\section{$\gg$ INSERT FIGURE $3<<$}

\subsection{Muscle damage}

The SOD3 gene showed an increase in CK from pre-exercise to post-exercise in CC genotype $(p<0.00 ; d=0.66)$ and GG + CG genotype $(p<0.00 ; d=0.82)$. The same occurred for $L D H$, regarding the CC genotype $(p<0.00 ; d=$ $0.74)$ and $G G+C G$ genotype $(p<0.00 ; d=1.10)$.

Both PPARa genotypes (GG: $p<0.00, d=0.60$; CC-GC: $p<0.00, d=0.63$ ) were associated with significant increases in muscle CK. The same occurred with LDH in the GG genotype $(p<0.00 ; d=0.72)$ and finally in the CC+GG genotype in the same time $(p<0.00 ; d=0.80)$. These data are shown in Figure 4.

\section{$\gg$ INSERT FIGURE $4<<$}

\subsection{Redox balance}

The CC genotype group for the SOD3 gene (showed less improvement in physical performance) increased significantly the TAC values in the post-exercise both in relation to the baseline moment and the pre-exercise moment $(p<0.00 ; d=1.00$ and $p<0.00 ; d=0.92)$, respectively (Figure 5 , panel $A)$. However, in the group interaction analysis, the TAC values in the post-exercise moment of the CC group were not increased in relation to the $\mathrm{GG}+\mathrm{CG}$ group.

In the analysis of the genotyped groups for PPARa, the TAC values increased in the post-exercise both in relation to the baseline and the pre-exercise in both groups: $C C+G G(p<0.00 ; d=0.81$ and $p<0.02 ; d=0.62)$, respectively, and for the GG genotype $(p<0.00 . d=0.92$ and $0.00 ; d=0.72)$, respectively. However, no difference occurred between genotypes (Figure 5, panel C).

The SOD3 or PPARa gene did not influence the responses to the malondialdehyde levels which did not undergo significant change in post-exercise. A single difference found was an increase in the baseline for pre-exercise in the CC genotype of SOD3 ( $p<0.02 ; d=0.22)$ and GG genotype of the PPARa gene $(p<0.00 ; d=0.30)$, but without differences in the comparison between groups. In addition, the exercise had not yet been carried out at that time.

Regarding plasmatic nitrite, only the $\mathrm{CC}+\mathrm{GC}$ genotype of the PPARa gene increased significantly from baseline to post-exercise $(p<0.01 ; d=0.69)$ and from pre-exercise to post-exercise $(p<0.00 ; d=0.73)$, but without differences in the comparison between groups.

\section{$\gg$ INSERT FIGURE $5<$}




\section{Discussion}

This study showed that grape juice promoted a longer time until exhaustion occurred. The effect was influenced by the GC + CG genotype of the SOD3 gene although an increase in antioxidant activity took place. This phenomenon did not explain the better performance presented by the GC + CG of the SOD3 gene group.

This study reinforces a trend of previous data reported in other research that indicate the ergogenic potential of purple grape juice to increase time-to-exhaustion in recreational runners [8] and vertical jump performance in handball athletes [43]. While the increase in performance occurred after four weeks of supplementation in these other studies, our research corroborated more recent data [9-44] that indicated the need for only a single dose of grape juice to notice the increase in the time-to-exhaustion in recreational runners and physically active men, respectively. It also confirmed in humans the previous data found on the increase in antioxidant activity observed in studies with animal models exposed to exercise $[5,6,45]$.

A wide variation in responsivity and magnitude of improvement shown to be responsive in previous studies [8,9] were also both noted in the present study. Approximately $30 \%$ of the athletes in other studies did not respond to grape juice ergogenic supplementation when compared to a placebo or control drink. This was also the case for the data from the present study.

Our data indicated that Arg213Gly polymorphism of the SOD3 gene was a significant influence on the effect of grape juice on running performance. These results highlighte that the substitution of arginine for glycine redistribute the matrix SOD3 enzyme to extracellular fluids [46], increasing the levels of the antioxidant enzyme superoxide dismutase [47]. In fact, the beneficial effect of antioxidant supplementation on the redox balance is dependent on endogenous adaptation [48], such as the regulation of signaling pathways for mitochondrial biogenesis in response to exercise $[49,50]$.

Interestingly, the CG + GG group of the SOD3 gene had a significantly lower percentage of fat than the CC group. This could be an influencing factor in the performance test result. To solve this issue, we performed a correction the test between the fat percentage and the performance delta, but we did not find any correlation between these variables $(R=-0,05 ; p<0,73)$.

The data demonstrated that the antioxidant response promoted by purple grape juice was not influenced by any of the genotypes studied. In fact, TAC was elevated in the post-exercise moment only in athletes with the CC genotype, and not in the GG+CG genotype that improved physical performance. However, the absence of differences between groups makes this data less consistent. Given this, we assumed that the redox balance was not a way to explain the best responsiveness of the GG+CG genotype of the SOD3 gene to grape juice in physical performance. Thus, the mechanisms explained this better responsiveness still needs to be further explored.

Despite these possibilities, our data showed that the markedly superior performance observed in subjects with the GG+CG genotype of SO3 gene was not accompanied by greater total antioxidant capacity or lower lipid peroxidation. A possible explanation for this paradoxical outcome is that the antioxidant action data mediated by SOD3 enzyme was not demonstrated in resting conditions. Therefore, this data cannot be directly attributed to exercise. 
Another possible explanation regarding this is in a methodological limitation because since the protocol was performed with humans, it was not possible to evaluate the redox balance conditions in muscle cells. As a result, the TAC and MDA plasma concentrations may not reflect muscle activity during exercise when representing the activity of the whole organism. Finally, it would be necessary to explore more direct biomarkers, such as superoxide dismutase, catalase, protein carbonylation and glutathione peroxidase.

Another way to research this includes the hypothetical possibility that the substances in grape juice could act directly on the aerobic and anaerobic energy production systems during exercise. This could contribute in some way to minimize muscle acidosis for the same exercise intensity.

In fact, oxidative stress is involved in muscle fatigue because it impairs muscle contraction mechanism, thus, contributing to the loss of physical performance during strenuous exercises [51]. However, further studies are needed to confirm this assumption, or even to determine other mechanisms involved in delayed fatigue pathways correlated to the effect of polyphenols, including the hypothesis of influence on muscle acidosis. In vitro protocols with a technique for measuring the reactivity of muscle samples in electrically stimulated organ bath conditions are an alternative to test these possibilities.

Our study showed that grape juice did not promote any protective effect on muscle damage. Furthermore, our results confirmed previous data from other studies [8,9]. However, these results must be viewed by the fact that the kinetics of serum creatine kinase activity has an increase in the first hours after exercise, followed by a peak at $24 \mathrm{~h}-48 \mathrm{~h}$ post exercise. As we did not measure it at this moment, we suggest caution with this result. As well, in future studies, this monitoring needs to happen not only for creatine kinase, but also for other markers of muscle damage in the 48 hours after exercise.

Regarding the PPARa gene results, the 7G/C polymorphism had no influence on the study variables. Our hypothesis was that the presence of the CC genotype would result in sport disadvantage because its phenotype implies an inferior response to the regulation of lipid metabolism, mitochondrial activity, biogenesis, antioxidant and anti-inflammatory defense [52]. Taken together, these phenotypes contributed to lower performance in exercise training. This was the goal of our research study. In addition, the use of a single dose of grape juice may not be enough to demonstrate an association with these phenotypes, such as improved redox balance and decreased damage muscle.

Although the present work does not confirm the association of this polymorphism with time-to-exhaustion in running, other research groups have demonstrated the influence of this polymorphism in sports performance. The frequency of the GG genotype for the PPARa gene in rowers, endurance athletes and soccer players is high [20]. This genotype is linked to improved performance by conserving glycogen reserves and using the oxidative pathway of fatty acids more efficiently. It is ideal for endurance activities $[53,54]$. However, these studies only examined polymorphism without considering nutrigenetics.

The data from our study, in particular with regard to the Arg213Gly polymorphism of the SOD3 gene, brings a new element to the current basis of sports nutrigenetics. Although some foods, nutraceuticals and supplements have functional or ergogenic properties, considerable individual variability is always present. There are individuals who do not respond to dietary interventions effectively [55]. 
Meanwhile, previous studies have already demonstrated the influence of other genes. Womack et al. [11] found that AA homozygotes of the CYP1A2 gene had better physical performance when compared to carriers of the $\mathrm{C}$ allele when supplemented with caffeine. Ribeiro et al. [12] observed that runners supplemented with pequi oil showed an aerobic advantage for the TG genotype EPO T/G polymorphism. Lifanov et al. [56] demonstrated that football players supplemented creatine exhibited aerobic advantage and less lactate accumulation for the CT genotype of the AMPD1 gene. Lifanov et al. [13] supplemented runners with glutathione and observed better responses to aerobic capacity for the Pro allele in Pro198Leu polymorphism of the GPX1 gene. Given this, our study is the first to present SOD3 (Arg123Gly) involved in the effect of nutritional treatments on the sports performance of running athletes.

Therefore, for practical purposes, genetic evaluation emerges in clinical practice as an additional tool for individualized prescription to optimize specific sports performance. Nevertheless, further studies are necessary to create a body of evidence in the field of sports nutrigenetics with the goal to implement them in the near future. Finally, implementing nutritional strategies based on a Athlete DNA can generate a competitive advantage. This reinforces the growth of nutrigenetics as the foundation that can help athletes improve their sports potential through dietary strategies aligned with their genetic characteristics.

\section{Conclusions}

In summary, we concluded that this study sheds new light on the following findings. First, it reinforced the results of recent studies, indicating that purple grape juice as a new food with ergogenic capacity. Second, it also reinforced the issue of individual variability in responsiveness to nutrients for sporting purposes. Finally, this study adds new outcomes to the literature, since it has identified a genetic polymorphism of the SOD3 gene as, at least, one possible genetic variant that explains the individual variability in responsiveness to purple grape juice.

\section{Declarations}

\section{Ethical approval}

The study was fully conducted in accordance with the Declaration of Helsinki, its protocol was approved by the Research Ethics Committee of the Center for Health Sciences, Federal University of Paraiba (protocol no.

2.196.523). The participants signed an informed consent form according to Resolution 466/12 of the National Health Council (Brazil) and informed consent was obtained from all volunteers before the inclusion in the study.

\section{Consent for publication}

Not applicable

\section{Availability of data and materials}

The datasets used and/or analyzed during the current study are available from the corresponding author on reasonable request.

\section{Competing interests}

The authors declare that they have no conflict of interest. 


\section{Funding}

This research was funded by Coordination for the Improvement of Higher Education Personnel level (CAPES) and the National Council for Scientific and Technological Development (CNPq).

\section{Authors' contributions}

Conceptualization: Bruno Rafael Virginio de Sousa and Alexandre Sérgio Silva; methodology: Bruno Rafael Virginio de Sousa, Lydiane L. Tavares Toscano and Alexandre Sérgio Silva; formal analysis: Bruno Rafael Virginio de Sousa, Lydiane L. Tavares Toscano, Klécia de Farias Sena, Matheus da Silveira Costa, Luana Heimfarth, Aline Telles Biasoto Marques and Darcilene Fiuza da Silva; investigation: Bruno Rafael Virginio de Sousa and Lydiane L. Tavares Toscano; resources, Bruno Rafael Virginio de Sousa, Alexandre Sérgio Silva, Jullyana de Souza Siqueira Quintans and Lydiane L. Tavares Toscano; data curation: Bruno Rafael Virginio de Sousa, Eder Jackson B. Almeida Filho, Rebeka Correia Souza Cunha; writing original draft preparation: Bruno Rafael Virginio de Sousa; writing review and editing: Bruno Rafael Virginio de Sousa, Alexandre Sérgio Silva, Lydiane L. Tavares Toscano, Eder Jackson B. Almeida Filho, Matheus da Silveira Costa, Luis Felipe Castelli Correia de Campos and Darlene Camati Persunh; supervision: Alexandre Sérgio Silva and Darlene Camati Persunh; funding acquisition, Alexandre Sérgio Silva. All authors have read and agreed to the published version of the manuscript.

\section{Acknowledgements}

The authors thank the Coordination for the Improvement of Higher Education Personnel level (CAPES) and the National Council for Scientific and Technological Development (CNPq) for the support and encouragement of this research. The authors also thank the Instituto Brasileiro do Vinho (IBRAVIN) together with the Government of the State of Rio Grande do Sul, with funds from the Agriculture Secretariat of Rio Grande do Sul, for supporting the execution of this work.

\section{References}

1. Callaghan C, Leggett R, Levin R. A Comparison of Total Antioxidant Capacities of Concord, Purple, Red, and Green Grapes Using the CUPRAC Assay. Antioxidants. 2013;2(4):257-264. doi:10.3390/antiox2040257.

2. Nassiri-Asl M, Hosseinzadeh Hossein. Review of the Pharmacological Effects of Vitis vinifera (Grape) and its Bioactive Compounds. Phyther Res. 2009;23(April):1197-1204. doi:10.1002/ptr.

3. Georgiev V, Ananga A, Tsolova V. Recent advances and uses of grape flavonoids as nutraceuticals. Nutrients. 2014;6(1):391-415. doi:10.3390/nu6010391.

4. Flamini R, Mattivi F, De Rosso M, Arapitsas P, Bavaresco L. Advanced knowledge of three important classes of grape phenolics: Anthocyanins, stilbenes and flavonols. Int J Mol Sci. 2013;14(10):19651-19669. doi:10.3390/ijms141019651.

5. Xianchu L, Ming L, Xiangbin L, Lan Z. Grape seed proanthocyanidin extract supplementation affects exhaustive exercise-induced fatigue in mice. Food Nutr Res. 2018;1(12):1-7.

6. Belviranlı M, Gökbel H, Okudan N, Başaralı K. Effects of grape seed extract supplementation on exerciseinduced oxidative stress in rats. Br J Nutr. 2018;108(2):249-256. doi:10.1017/S0007114511005496. 
7. Veskoukis AS, Kyparos A, Nikolaidis MG, Stagos D, Aligiannis N, Halabalaki M, et al. The Antioxidant Effects of a Polyphenol-Rich Grape Pomace Extract In Vitro Do Not Correspond In Vivo Using Exercise as an Oxidant Stimulus. Oxid Med Cell Longev. 2012;2012:185867. doi:10.1155/2012/185867.

8. Toscano LDLT, Silva AS, França ACL De, Sousa BRV de, Almeida Filho EJB de, Costa M da S, et al. A single dose of purple grape juice improves physical performance and antioxidant activity in runners: a randomized, crossover, double-blind, placebo study. Eur J Nutr. 2019;15(1):1-11. doi:10.1007/s00394-019-02139-6.

9. Toscano LT, Tavares RL, Toscano LT, Silva CSO da, Almeida AEM de, Biasoto ACT, et al. Potential ergogenic activity of grape juice in runners. Appl Physiol Nutr Metab. 2015;40(9):899-906. doi:10.1139/apnm-20150152.

10. Cavalcante IGM, Silva AS, Costa MJC, Persuhn DC, Issa IC, Freire TL de L, et al. Effect of vitamin D3 supplementation and in $\mathrm{fl}$ uence of Bsml polymorphism of the VDR gene of the in $\mathrm{fl}$ ammatory pro fi le and oxidative stress in elderly women with vitamin D insuf fi ciency Vitamin D3 megadose reduces in fl ammatory markers. Exp Gerontol j. 2015;66(8):10-16. doi:10.1016/j.exger.2015.03.011.

11. Womack CJ, Saunders MJ, Bechtel MK, Bolton DJ, Martin M, Luden ND, et al. The influence of a CYP1A2 polymorphism on the ergogenic effects of caffeine. J Int Soc Sports Nutr. 2012;9(1):1-6. doi:10.1186/15502783-9-7.

12. Ribeiro IF, Miranda-Vilela AL, Klautau-Guimarães MDN, Grisolia CK. The influence of erythropoietin (EPO $\mathrm{T} \rightarrow \mathrm{G}$ ) and a-Actinin-3 (ACTN3 R577X) polymorphisms on runners' responses to the dietary ingestion of antioxidant supplementation based on pequi oil (Caryocar brasiliense Camb.): A before-after study. J Nutrigenet Nutrigenomics. 2014;6(6):283-304. doi:10.1159/000357947.

13. Lifanov AD, Khadyeva MN, Rakhmatullina LS, Demenev S V, Khamidullina GF, Chekulaeva AM, et al. Influence of the GPX1 gene polymorphism to aerobic capacity and efficiency of glutathione supplementation in athletes. Ross Fiziol zhurnal Im IM Sechenova. 2014;100(2):248-255.

14. Dong XL, Li DJ, Liu H, Zhao YY. SOD3 and eNOS genotypes are associated with SOD activity and NOx. Exp Ther Med. 2014;8(1):328-334. doi:10.3892/etm.2014.1720.

15. Yamada, H., Yamada, Y., Adachi, T., Goto, H. Ogasawara N, Futenma A, et al. Molecular analysis of extracellular-superoxide dismutase gene associated with high level in serum. The Japanese Journal of Human Genetics. 1995; 40(2), 177-184. https://doi.org/10.1007/BF01883574

16. Sandström, J., Nilsson, P., Karlsson, K., \& Marklund, S. L. 10-Fold increase in human plasma extracellular superoxide dismutase content caused by a mutation in heparin-binding domain. Journal of Biological Chemistry. 1994; 269(29), 19163-19166. https://doi.org/10.1016/s0021-9258(17)32289-5

17. Kim T, Qinglin Y. Peroxisome-proliferator-activated receptors regulate redox signaling in the cardiovascular system. World J Cardiol. 2013;5(6):164-174. doi:10.4330/wjc.v5.i6.164.

18. Russell AP, Feilchenfeldt J, Schreiber S, Praz M, Crettenand A, Gobelet C, et al. Endurance Training in Humans Leads to Fiber Type-Specific Increases in Levels of Peroxisome Proliferator-Activated Receptor-y Coactivator1 and Peroxisome Proliferator-Activated Receptor-a in Skeletal Muscle. Diabetes. 2003;52(12):2874-2881. doi:10.2337/diabetes.52.12.2874.

19. Ahmetov II, Mozhayskaya IA, Flavell DM, Astratenkova I V., Komkova Al, Lyubaeva E V., et al. PPARa gene variation and physical performance in Russian athletes. Eur J Appl Physiol. 2006;97(1):103-108. doi:10.1007/s00421-006-0154-4. 
20. Ahmetov II, Fedotovskaya ON. Current Progress in Sports Genomics. Adv Clin Chem. 2015;70:247-314. doi:10.1016/bs.acc.2015.03.003.

21. Weltman A, Snead D, Seip R, Schurrer R, Levine S, Rutt R, et al. Prediction of Lactate Threshold and Fixed Blood Lactate Concentrations from 3200-m Running Performance in Male Runners. Int J Sports Med. 1987;08(06):401-406. doi:10.1055/s-2008-1025694.

22. Gibson RS. Principles of Nutritional Assessment. $2^{\mathrm{a}}$ ed. Oxford University Press, United States, 2005.

23. Brand-Williams W, Cuvelier ME, Berset C. Use of a Free Radical Method to Evaluate Antioxidant Activity. LWT - Food Sci Technol. 1995;28(1):25-30.

24. Miller, N.J.; Rice-Evans, C.; Davie, M.J.; Gopinathan, V.; Milner, A. A novel method for measuring antioxidant capacity and its application to monitoring the antioxidant status in premature neonates. Clin Sci. 1993;84(4):407-412. doi:10.1042/cs0840407

25. Rufino, M SM.; Alves, R.E.; Brito, E.S.; Pérez-Jiménez, J.; Saura-Calixto, F.; Mancini-Filho, J. Bioactive compounds and antioxidant capacities of 18 non-traditional tropical fruits from Brazil. Food Chem. 2010;121(4):996-1002. doi:10.1016/j.foodchem.2010.01.037

26. Singleton, V.L.; Rossi, J.A. Colorimetry of Total Phenolics with Phosphomolybdic-Phosphotungstic Acid Reagents. Am J Enol Vitic. 1965;16(3):144-158.

27. Stalmach A, Edwards CA, Wightman JD, Crozier A. Gastrointestinal stability and bioavailability of (poly) phenolic compounds following ingestion of Concord grape juice by humans. Mol Nutr Food Res. 2012;53(3):497-509. doi:10.1002/mnfr.201100566.

28. Viana MF, Almeida P, Santos RC. Adaptação portuguesa da versão reduzida do Perfil de Estados de Humor POMS. Análise Psicológica. 2012;19(1):77-92. doi:10.14417/ap.345.

29. Costa LOP, Samulski DM. Processo de Validação do Questionário de Estresse e Recuperação para Atletas ( RESTQ-Sport ) na Língua Portuguesa. Rev Bras Ciência e Mov. 2006;13(1):79-86. doi:10.18511/rbcm.v13i1.615.

30. Bertolazi AN, Fagondes SC, Hoff LS, Pedro VD, Saldanha S, Barreto M, et al. Portuguese-language version of the Epworth sleepiness scale: validation for use in Brazil. J Bras Pneumol. 2009;35(9):877-883.

31. Candow DG, Kleisinger AK, Grenier S, Dorsch KD. Effect of sugar-free Red Bull energy drink on high-intensity run time-to-exhaustion in young adults. J Strength Cond Res. 2009;23(4):1271-

1275. doi:10.1519/JSC.0b013e3181a026c2.

32. Kelly J, Vanhatalo A, Bailey SJ, Wylie LJ, Tucker C, List S, et al. Dietary nitrate supplementation: Effects on plasma nitrite and pulmonary 02 uptake dynamics during exercise in hypoxia and normoxia. Am J Physiol Regul Integr Comp Physiol. 2014;307(7):R920-R930. doi:10.1152/ajpregu.00068.2014.

33. Jetté M, Sidney K, Blümchen G. Metabolic equivalents (METS) in exercise testing, exercise prescription, and evaluation of functional capacity. Clin Cardiol. 1990;13(8):555-565. doi:10.1002/clc.4960130809.

34. Borg G. Psychophysical bases of perceived exertion. Med Sci Sport Exerc. 1982;14(5):377-381.

35. Laddha NC. Role of superoxide dismutases tumor necrosis factor-a and-b vitiligo susceptibility. P.h D. These, The Maharaja Sayajirao University of Baroda, Vadodara, Índia, 2015.

36. Pishva H, Mahboob SA, Mehdipour P, Eshraghian MR, Mohammadi-asl J, Hosseini S, et al. Association between the FABP2 Ala54Thr, PPAR a Leu162/Val, and PPAR a intron7 polymorphisms and blood lipids 
ApoB and ApoCIII in hypertriglyceridemic subjects in Tehran. J Clin Lipidol. 2009;3(3):187-194. doi:10.1016/j.jacl.2009.04.001.

37. Ohkawa H, Ohishi N, Yagi K. Assay for Lipid Peroxides in Animal Tissues Thiobarbituric Acid Reaction. Anal Biochem. 1979;95(2):351-358.

38. Green L, Tannenbaum, Goldman P. Nitrate synthesis in the germfree and conventional rat. Science (80-). 1981;212(4490):56-58. doi:10.1126/science.6451927.

39. Templeton GF. A Two-Step Approach for Transforming Continuous Variables to Normal: Implications and Recommendations for IS Research. Commun Assoc Inf Syst. 2011;28(1):41-58. doi:10.17705/1CAIS.02804.

40. Cook BG, Cook L, Therrien WJ. Group-Difference Effect Sizes: Gauging the Practical Importance of Findings from Group-Experimental Research. Learn Disabil Res Pract. 2018;00(0):1-8.

41. Støa EM, Støren $\varnothing$, Enoksen E, Ingjer F. Percent utilization of VO2 max at 5-km competition velocity does not determine time performance at 5 km among elite distance runners. J Strength Cond Res. 2010;24(5):13401345. doi:10.1519/JSC.0b013e3181cc5f7b.

42. Tanda G, Knechtle B. Marathon performance in relation to body fat percentage and training indices in recreational male runners. Open Access J Sport Med. 2013;4:141-149.

43. Lafay S, Jan C, Nardon K, Lemaire B, Ibarra A, Roller M, et al. Grape extract improves antioxidant status and physical performance in elite male athletes. J Sports Sci Med. 2009;8(3):468-480.

44. Deley G, Guillemet D, Allaert F-A, Babault N. An Acute Dose of Specific Grape and Apple Polyphenols Improves Endurance Performance: A Randomized, Crossover, Double-Blind versus Placebo Controlled Study. Nutrients. 2017;9(8):917-926. doi:10.3390/nu9080917

45. Minegishi Y, Haramizu S, Hase T, Murase T. Red grape leaf extract improves endurance capacity by facilitating fatty acid utilization in skeletal muscle in mice. Eur J Appl Physiol. 2011;111(9):1983-1989. doi:10.1007/s00421-011-1826-2

46. Garcia AM, Allawzi XA, Tatman P, Hernandez-lagunas L, Swain K, Mouradian G, et al. R213G polymorphism in SOD3 protects against bleomycin-induced inflammation and attenuates induction of proinflammatory pathways. Physiol Genomics. 2018;50(9):807-816. doi: 10.1152/physiolgenomics.00053.2018.

47. Kwon M, Kim B, Lee YS, Kim T. Role of superoxide dismutase 3 in skin inflammation. J Dermatol Sci. 2012;67(2):81-87. doi:10.1016/j.jdermsci.2012.06.003

48. Kuo Y, Lin J, Bernard JR, Liao Y. Green tea extract supplementation does not hamper endurance-training adaptation but improves antioxidant capacity in sedentary men. J Appl Physiol Metab. 2015;40(10):990996. doi:10.1139/apnm-2014-0538

49. Gomez-Cabrera MC, Salvador-Pascual A, Cabo H, Ferrando B, Viña J. Redox modulation of mitochondriogenesis in exercise. Doesantioxidantsupplementation blunt thebenefits of exercise training? Free Radic Biol Med. 2015;86:37-46. doi:10.1016/j.freeradbiomed.2015.04.006

50. Radak Z, Ishihara K, Tekus E, Varga C, Posa A, Balogh L, et al. Redox Biology Exercise, oxidants, and antioxidants change the shape of the bell-shaped hormesis curve. Redox Biol. 2017;12(February):285-290. doi:10.1016/j.redox.2017.02.015

51. Wan J, Qin Z, Wang P, Sun Y, Liu X. Muscle fatigue: general understanding and treatment. Exp Mol Med. 2017;49(10):e384. doi:10.1038/emm.2017.194

Page 17/25 
52. Maciejewska-Karlowska A. Polymorphic variants of the PPAR (Peroxisome Proliferator-Activated Receptor) genes: relevance for athletic performance. Trends Sport Sci. 2013;1:5-15.

53. Maciejewska A, Sawczuk M. Variation in the PPARa gene in Polish rowers. J Sci Med Sport. 2011;14(1):5864. doi:10.1016/j.jsams.2010.05.006.

54. Proia P, Bianco A, Schiera G, Saladino P, Contrò V, Caramazza G, et al. PPARa gene variants as predicted performance-enhancing polymorphisms in professional Italian soccer players. Open Access J Sport Med. 2014;5:273-278.

55. Kerksick CM, Wilborn CD, Roberts MD, Smith-Ryan A, Kleiner SM, Jäger R, et al. ISSN exercise \& sports nutrition review update: Research \& recommendations. J Int Soc Sports Nutr. 2018;15(1):1-57. doi:10.1186/s12970-018-0242-y.

56. Lifanov D, Khadyeva MN, Rahmatullina LS, Demenev S V., Ibragimov RR. Effect of creatine supplementation on physical performance are related to the AMPD1 and PPARG genes polymorphisms in football players. Ross Fiziol zhurnal Im IM Sechenova. 2014;100(6):767-776. Accessed November 5, 2020.

\section{Tables}

Table 1. Antioxidant characteristics of purple grape juice.

Total monomeric anthocyanins (mg/L)

ND

Trans-Resveratrol (mg/L)

0.5

Cis-Resveratrol (mg/L)

0.3

Caffeic acid (mg/L)

4.0

Caftaric acid (mg/L)

67.1

Chlorogenic acid (mg/L)

8.4

Proanthocyanidin B1 (mg/L)

2.6

Proanthocyanidin B2 (mg/L)

2,4

Epigallocatechin gallate (mg/L)

1.8

Catechin (mg/L)

1.3

Isoquercetin (mg/L)

ND = not detected. Dates obtained for HPLC high-performance liquid chromatography, EMBRAPA = empresa brasileira de pesquisa agropecuária 
Table 2. Baseline characteristics of athletes from the general group and the genotyped experimental group.

\begin{tabular}{|c|c|c|c|c|c|}
\hline & \multirow{3}{*}{$\begin{array}{l}\text { General } \\
(n=47)\end{array}$} & \multicolumn{2}{|c|}{ SOD3 Genotypes } & \multicolumn{2}{|c|}{ PPARa Genotypes } \\
\hline & & $\mathrm{CG}+\mathrm{GG}$ & CC & $\mathrm{GC}+\mathrm{CC}$ & GG \\
\hline & & $(n=12)$ & $(n=35)$ & $(n=24)$ & $(n=23)$ \\
\hline Age (years) & $35.2 \pm 8.6$ & $34.5 \pm 7.9$ & $35.4 \pm 8.9$ & $35.4 \pm 9.1$ & $34.9 \pm 8.2$ \\
\hline $\mathrm{BMI}\left(\mathrm{kg} \cdot \mathrm{m}^{2}\right)$ & $23.3 \pm 2.7$ & $22.6 \pm 2.1$ & $23.5 \pm 2.8$ & $22.9 \pm 2.7$ & $23.6 \pm 2.7$ \\
\hline Body fat (\%) & $15.1 \pm 5.3$ & $12.3 \pm 6.0$ & $16.0 \pm 4.7^{\star}$ & $14.3 \pm 5.5$ & $15.8 \pm 5.1$ \\
\hline RHR (bpm) & $56.3 \pm 7.6$ & $56.0 \pm 6.0$ & $56.4 \pm 8.2$ & $57.7 \pm 7.8$ & $55.9 \pm 7.4$ \\
\hline $\mathrm{VO}_{2} \max \left(\mathrm{ml} \cdot \mathrm{kg}^{-1} \cdot \mathrm{min}^{-1}\right)$ & $51.9 \pm 7.6$ & $54.4 \pm 8.3$ & $51.0 \pm 7.3$ & $51.3 \pm 7.7$ & $52.5 \pm 7.6$ \\
\hline Training (years) & $7.1 \pm 6.4$ & $6.5 \pm 5.0$ & $7.3 \pm 6.8$ & $6.4 \pm 6.1$ & $7.8 \pm 6.7$ \\
\hline Training frequency (days/week) & $4.3 \pm 1.1$ & $4.4 \pm 1.0$ & $4.3 \pm 1.1$ & $4.1 \pm 1.0$ & $4.5 \pm 1.2$ \\
\hline Training volume (km/week) & $40.5 \pm 20.4$ & $\begin{array}{l}43.7 \pm \\
15.9\end{array}$ & $39.4 \pm 21.8$ & $\begin{array}{l}40.0 \pm \\
20.1\end{array}$ & $\begin{array}{l}40.4 \pm \\
21.2\end{array}$ \\
\hline $\begin{array}{l}\text { Complementary activity } \\
\text { (min/week) }\end{array}$ & $\begin{array}{l}128.6 \pm \\
96.7\end{array}$ & $116.0 \pm 86$ & $\begin{array}{l}135.1 \pm \\
101^{*}\end{array}$ & $137 \pm 92.9$ & $120 \pm 102$ \\
\hline Work (h/day) & $6.9 \pm 2.3$ & $6.9 \pm 2.4$ & $6.9 \pm 2.3$ & $7.2 \pm 2.0$ & $6.6 \pm 2.5$ \\
\hline
\end{tabular}


Table 3. Baseline variables of biochemical markers, nutritional status and physiological self-reported conditions of athletes.

\begin{tabular}{llllll} 
& & \multicolumn{2}{c}{ Genotype SOD3 } & \multicolumn{2}{c}{ Genotype PPARa } \\
Control & Grape juice & GG+CG & CC & CC+GC & GG \\
$(n=47)$ & $(n=47)$ & $(n=12)$ & $(n=35)$ & $(n=24)$ & $(n=23)$
\end{tabular}

\section{Plasma biomarkers}

\begin{tabular}{lllllll} 
TAC $(\%)$ & $27.9 \pm 9.3$ & $30.4 \pm 10.6$ & $30.2 \pm 10.3$ & $30.5 \pm 10.9$ & $29.4 \pm 8.4$ & $31.5 \pm 12.7$ \\
\hline MDA $(\mu \mathrm{mol} / \mathrm{L})$ & $3.7 \pm 1.3$ & $3.7 \pm 1.3$ & $4.0 \pm 1.0$ & $3.6 \pm 1.4$ & $3.8 \pm 1.3$ & $3.8 \pm 1.3$ \\
\hline $\mathrm{NO}(\mu \mathrm{mol} / \mathrm{L})$ & $11.4 \pm 5.2^{*}$ & $9.6 \pm 4.4$ & $9.3 \pm 4.9$ & $9.7 \pm 4.2$ & $9.5 \pm 4.1$ & $9.7 \pm 4.7$ \\
$\mathrm{CK}(\mathrm{U} / \mathrm{L})$ & $175.5 \pm 77 *$ & $162.1 \pm 55.4$ & $155.6 \pm 61.5$ & $164.3 \pm 53.9$ & $169.8 \pm 59.4$ & $154.4 \pm 51.4$ \\
$\mathrm{LDH}(\mathrm{U} / \mathrm{L})$ & $286.3 \pm 44.6$ & $293.5 \pm 53.8$ & $277.6 \pm 60$ & $299.1 \pm 51.2$ & $299.1 \pm 46.9$ & $287.9 \pm 60.4$
\end{tabular}

\section{Nutritional intake}

\begin{tabular}{|c|c|c|c|c|c|c|}
\hline $\begin{array}{l}\text { Energy } \\
(\text { kcal/kg/d) }\end{array}$ & $34.3 \pm 13$ & $31.9 \pm 9.6$ & $32.6 \pm 14.5$ & $31.7 \pm 7.5$ & $30.6 \pm 10.3$ & $33.3 \pm 8.8$ \\
\hline $\begin{array}{l}\text { carbohydrate } \\
(\mathrm{g} / \mathrm{kg} / \mathrm{d})\end{array}$ & $4.6 \pm 2.0$ & $4.3 \pm 1.6$ & $5.4 \pm 1.8 *$ & $3.9 \pm 1.4$ & $4.6 \pm 1.5$ & $4.0 \pm 1.7$ \\
\hline Protein $(\mathrm{g} / \mathrm{kg} / \mathrm{d})$ & $1.4 \pm 0.5$ & $1.3 \pm 0.5$ & $1.3 \pm 0.5$ & $1.3 \pm 0.4$ & $1.1 \pm 0.4$ & $1.5 \pm 0.4$ \\
\hline Fat $(\mathrm{g} / \mathrm{kg} / \mathrm{d})$ & $1.1 \pm 0.6$ & $1.0 \pm 0.5$ & $1.1 \pm 0.4$ & $1.0 \pm 0.5$ & $1.0 \pm 0.5$ & $1.0 \pm 0.4$ \\
\hline Vitamin A (RE/d) & $1414 \pm 4734$ & $1154 \pm 2421$ & $647 \pm 2521$ & $1313 \pm 2404$ & $1038 \pm 2.699$ & $1269 \pm 2162$ \\
\hline $\begin{array}{l}\text { Vitamin } C \\
(\mathrm{mg} / \mathrm{d})\end{array}$ & $110.6 \pm 120$ & $90.5 \pm 101$ & $110.3 \pm 90$ & $84.3 \pm 105.6$ & $65.3 \pm 105.5$ & $118 \pm 92.1$ \\
\hline $\begin{array}{l}\text { Vitamin D } \\
(\mathrm{mcg} / \mathrm{d})\end{array}$ & $7.1 \pm 28.5$ & $12.4 \pm 35.8$ & $13.3 \pm 40.4$ & $12.2 \pm 34.9$ & $11 \pm 33.8$ & $13.9 \pm 38.8$ \\
\hline $\begin{array}{l}\text { Vitamin } E \\
(\mathrm{mg} / \mathrm{d})\end{array}$ & $19.9 \pm 21.4$ & $14.5 \pm 13.4$ & $13.4 \pm 11$ & $14.9 \pm 14.3$ & $15.1 \pm 13.6$ & $13.9 \pm 13.4$ \\
\hline Cooper (mg/d) & $1.7 \pm 4.0$ & $1.1 \pm 1.1$ & $1.2 \pm 0.7$ & $1.1 \pm 1.2$ & $1.1 \pm 1.2$ & $1.2 \pm 0.9$ \\
\hline Selenium $(\mu \mathrm{cg} / \mathrm{d})$ & $76.2 \pm 37.5$ & $61.7 \pm 43.9$ & $66.5 \pm 50.3$ & $60.1 \pm 42.2$ & $64.9 \pm 44.9$ & $58.6 \pm 43.7$ \\
\hline $\begin{array}{l}\text { Manganese } \\
(\mathrm{mg} / \mathrm{d})\end{array}$ & $109.4 \pm 5.1$ & $111.6 \pm 109.4$ & $150.6 \pm 105.7$ & $99.3 \pm 109.1$ & $104.3 \pm 104$ & $118 \pm 116.4$ \\
\hline Zinc (mg/d) & $8.8 \pm 5.1$ & $8.0 \pm 4.0$ & $9.0 \pm 3.4$ & $7.6 \pm 4.1$ & $6.5 \pm 3.3$ & $9.6 \pm 3.8 *$ \\
\hline \multicolumn{7}{|c|}{ Sleep, mood, general stress and physical recovery } \\
\hline Sleep $(h / d)$ & $7.1 \pm 1.2$ & $7.2 \pm 1.2$ & $7.2 \pm 1.0$ & $7.5 \pm 1.2^{\star}$ & $7.2 \pm 1.4$ & $7.3 \pm 1.0$ \\
\hline ESS-BR (score) & $5.4 \pm 3.2$ & $5.5 \pm 3.1$ & $5.1 \pm 3.0$ & $7.0 \pm 3.3$ & $6.6 \pm 3.2^{\star}$ & $4.5 \pm 2.7$ \\
\hline PTH (score) & $90.3 \pm 15.2$ & $90.8 \pm 16.4$ & $102 \pm 21.5^{\star}$ & $86.9 \pm 12.5$ & $92.1 \pm 17$ & $89.5 \pm 18$ \\
\hline Stress RESTQ- & $0.7 \pm 0.7$ & $0.8 \pm 0.8$ & $1.0 \pm 0.9$ & $0.6 \pm 0.7$ & $0.8 \pm 0.8$ & $0.5 \pm 0.7$ \\
\hline
\end{tabular}


sport (score)

Recovery

RESTQ-sport

$3.5 \pm 0.9$

$3.7 \pm 0.9$

$3.5 \pm 0.9$

$3.5 \pm 0.9$

$3.6 \pm 1.0$

$3.7 \pm 0.8$

(escore)

$\mathrm{TAC}=$ Total Antioxidant Capacity, MDA = malondialdehyde, $\mathrm{TAC}=$ total antioxidant capacity, $\mathrm{CK}=$ creatine kinase, $\mathrm{LDH}=$ lactate dehydrogenase, ESS-BR = Epworth sleepiness scale-brazilian, PTH = Perturbação Total de Humor, RESTQ-sport = recovery-stress questionnaire for athletes. Data are presented as mean \pm SD. $\left({ }^{\star}\right)$ indicates statistical difference considering $(p<0.05)$ in the $t$ test for independent samples.

\section{Figures}

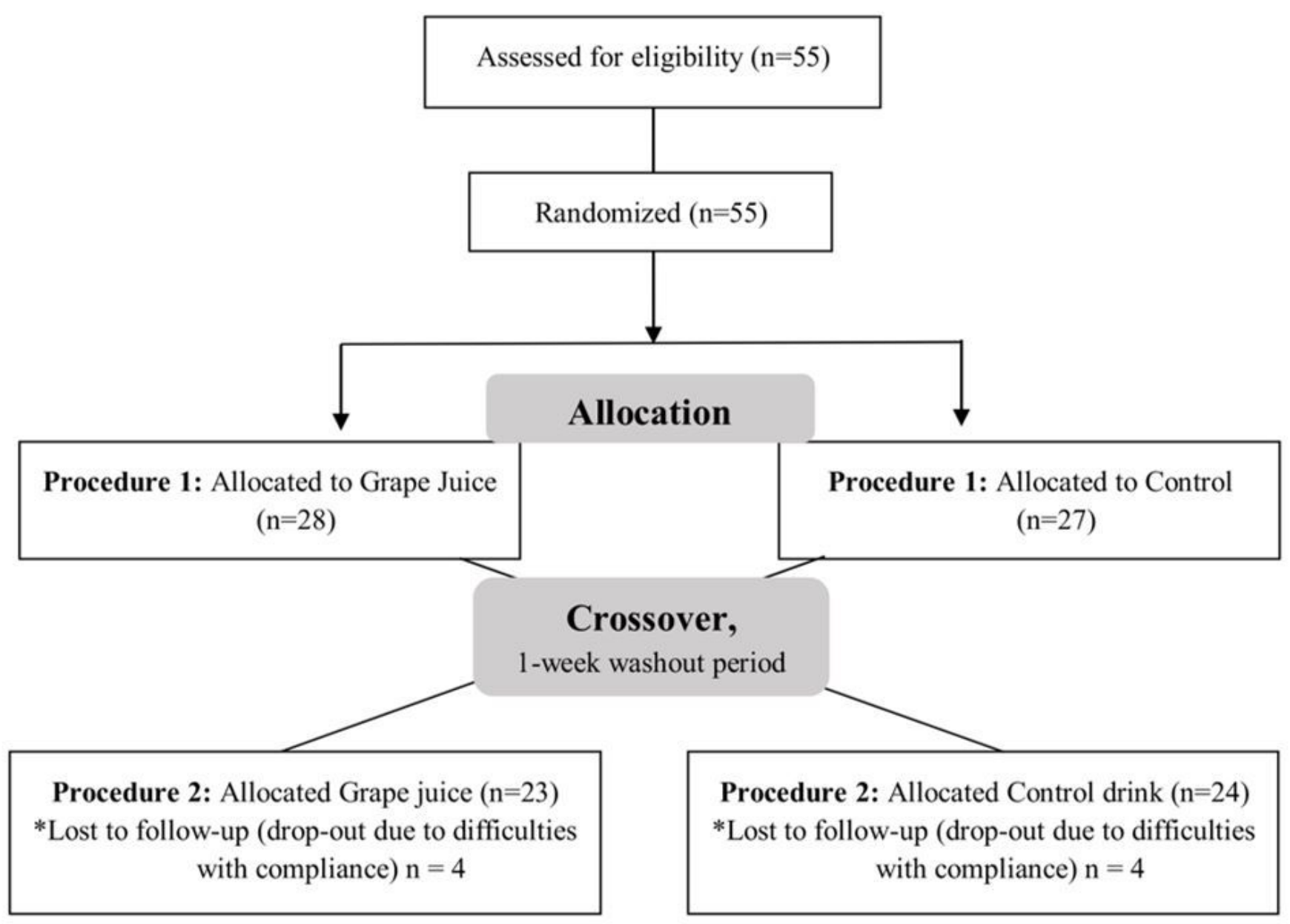

Analyzed

Figure 1

Analysed $(n=47), 23$ started with grape juice and 24 started with control drink 


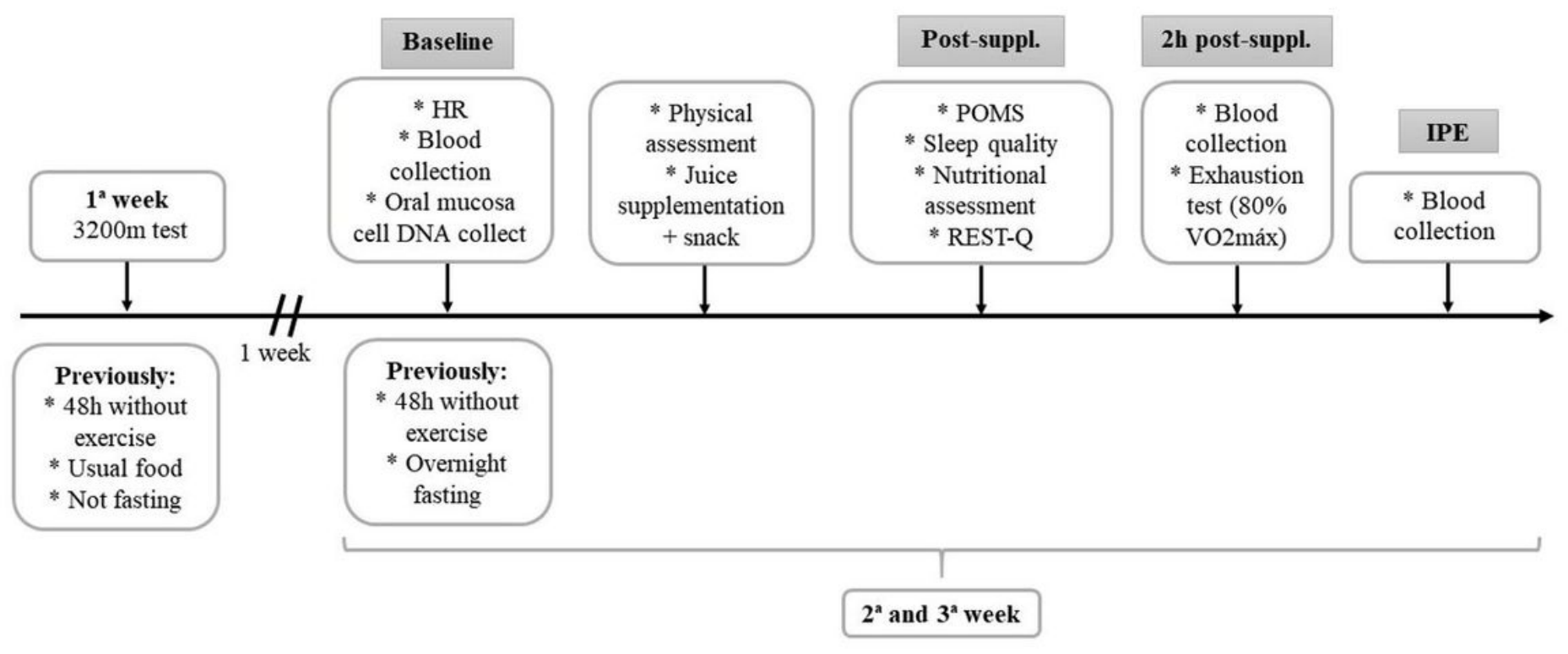

\section{Figure 2}

Experimental design. $\mathrm{HR}=$ Heart Rate, $\mathrm{POMS}=$ profile of mood states, RESTQ = sport recovery-stress

questionnaire for athletes, $\mathrm{VO}_{2} \mathrm{max}=$ maximum oxygen volume, Post-suppl. $=$ Post-supplementation, $2 \mathrm{~h}$ postsuppl. = 2 hours post-supplementation; IPE = immediately post-exercise. 

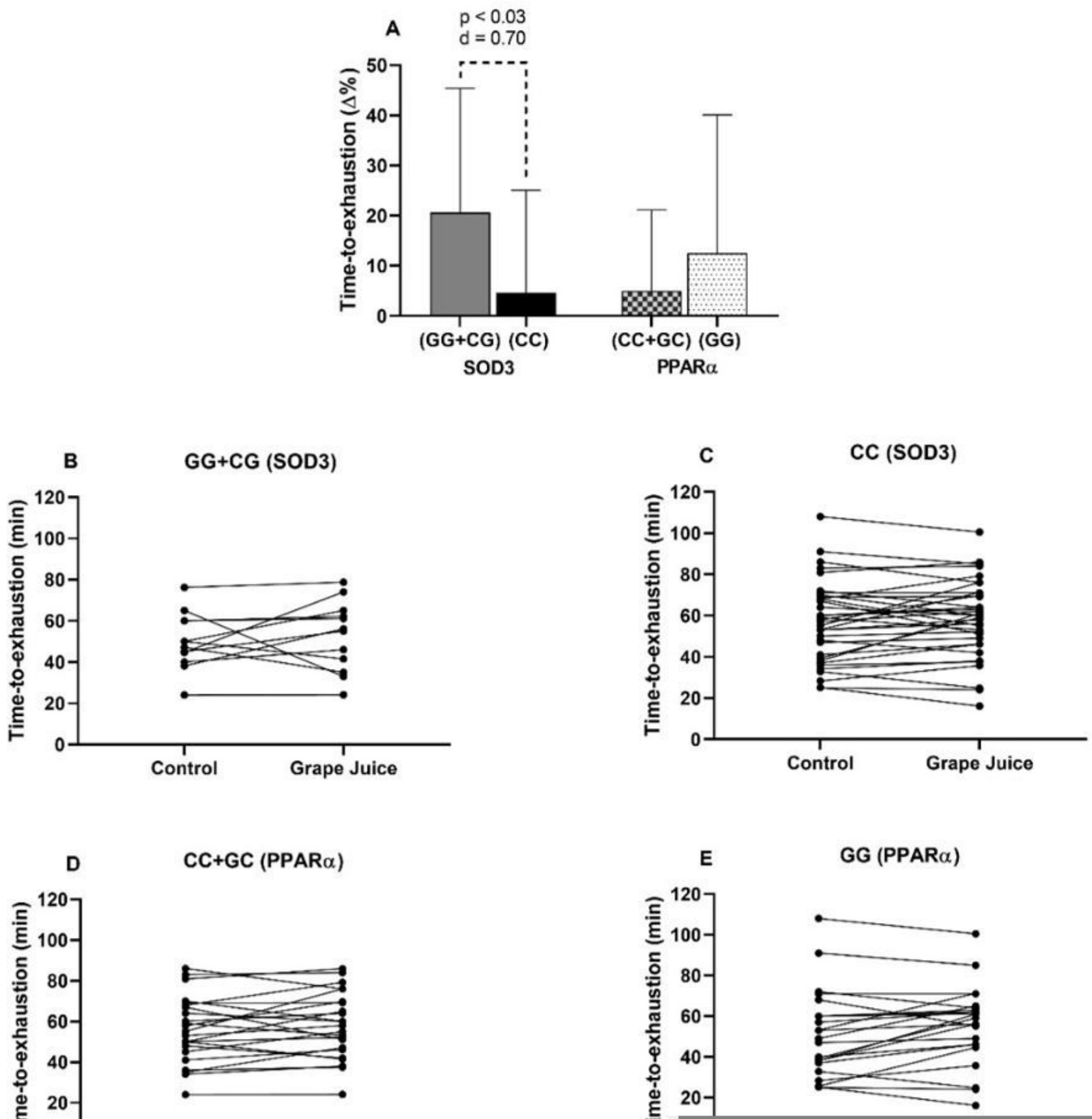

\section{Figure 3}

Time-to-exhaustion of recreational runners after supplementation with a single dose of whole purple grape juice, according to the genotypes for the SOD3 and PPARa genes (mean \pm standard deviation). Panel A - relative variation from time-to-exhaustion in the genotyped groups; Panels $B$ and $C$ - individual analysis of the time until exhaustion, of each athlete for the SOD3 genotype; Panels D and E - individual analysis of the time until exhaustion, of each athlete for the PPARa genotypes. $p<0.05$ - indicates a significant difference between the groups analyzed by a paired $t$ test $(n=47)$. 

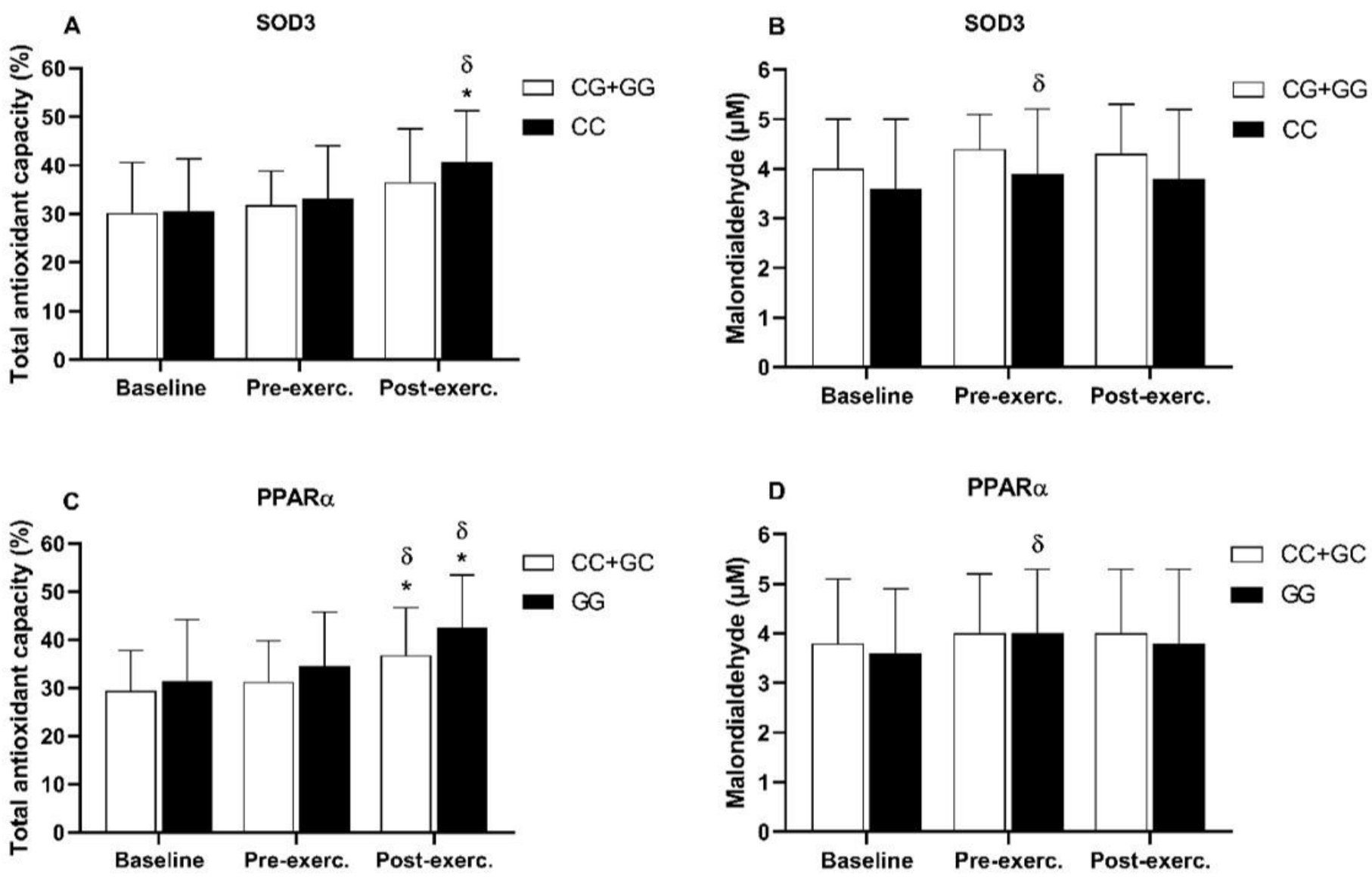

Figure 4

Effects of whole purple grape juice on muscle damage (mean \pm standard deviation). Panel A and C - creatine kinase; Panel B and D - lactate dehydrogenase. $(\delta)$ indicates a significant difference intra-group compared with moment immediately previous; $\left(^{*}\right)$ indicates intra-group difference at post-exercise compared with baseline. $p<$ $0.05)$ analyzed by a two-way ANOVA for repeated measurements $(n=47)$. 

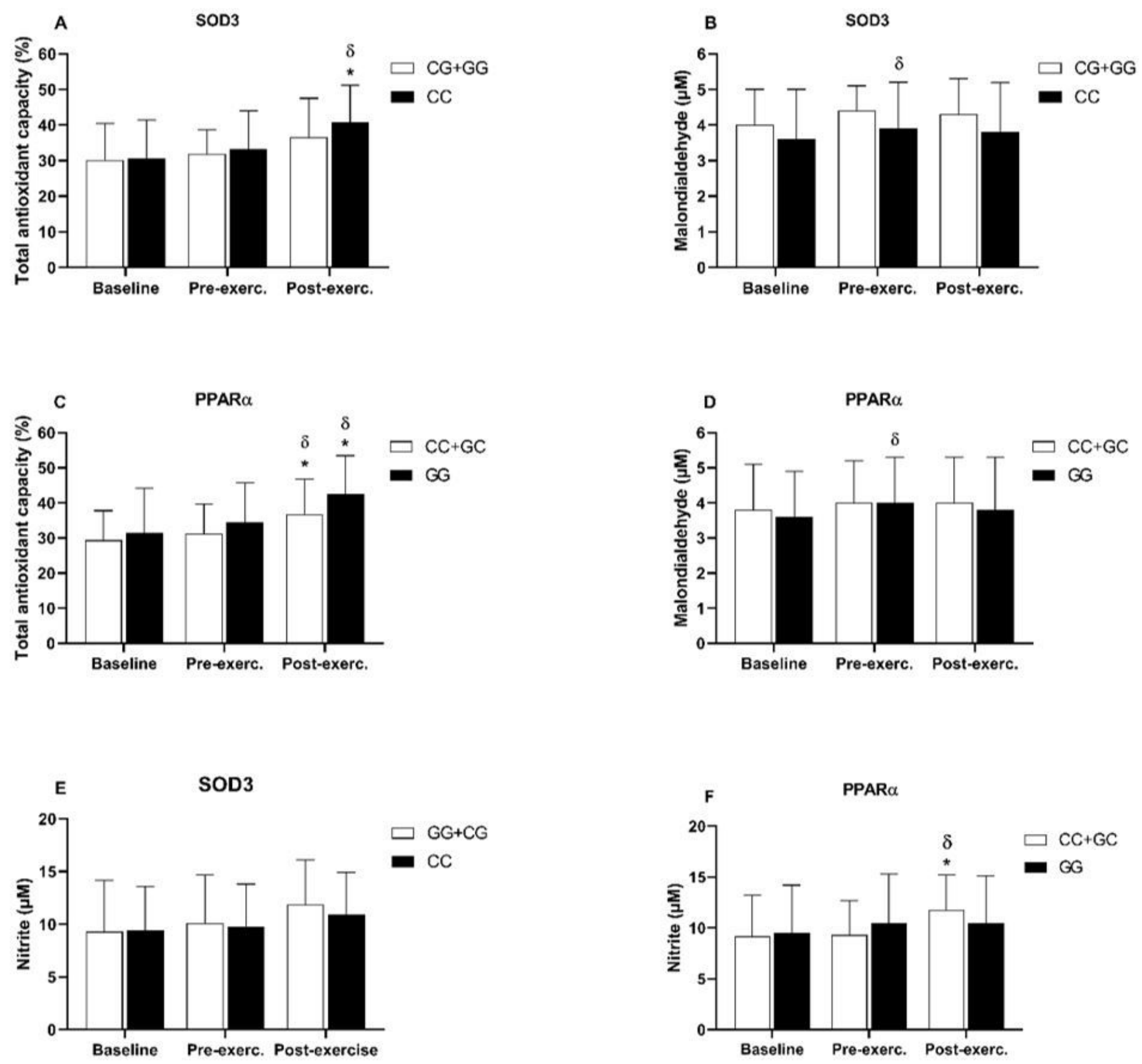

Figure 5

Effects of whole purple grape juice on oxidative stress (mean \pm SD). Panel A and C, antioxidant capacity; panel B and $D$, lipid peroxidation; $E$ and $F$, nitrite plasmatic. ( $\delta$ ) indicates a significant difference intra-group compared with moment immediately previous; ${ }^{*}$ ) indicates intra-group difference at post-exercise compared with baseline. $(p<0.05)$ analyzed by a two-way ANOVA for repeated measurements $(n=47)$. 